\title{
Study on the Influence of Environment Temperature on Welding Deformation and Stress of Box Structure
}

\author{
Yuanbin FANG ${ }^{1,2, a}$, Yong WANG ${ }^{3, b}$, Can WANG ${ }^{1,2, c}$ and Guizhi ZHANG ${ }^{1,2, d}$ \\ ${ }^{1}$ Jiangsu Xuzhou Engineering Machinery Research Institute, Jiangsu Xuzhou 221004, China \\ ${ }^{2}$ State key Laboratory of Intelligent Manufacturing of Advanced Construction Machinery, XCMG \\ Construction Machinery Co., Ltd, Jiangsu Xuzhou 221004, China \\ ${ }^{3}$ XCMG Xuzhou Mining Machinery Co. Ltd, Jiangsu Xuzhou 221004, China \\ afybflying@163.com, 'benmebanyanhou@126.com, ${ }^{\mathrm{c}} 18251591969 @ 163 . c o m$, \\ dzgz0115@163.com
}

Keywords: Environment temperature; box structure; welding deformation; stress

Abstract. Numerical simulation welding process of box structure at different environment temperature, it obtains and tests deformation and stress distribution of ironing plate. The results show that deformation trend is convex on the bottom of $\mathrm{U}$-shaped plate, and deformation is concave in the center of connecting plates on both sides. The maximum deformation position occurs the connecting plate extends from one end of the upper side. Deformation peak values at environmental temperature of $0^{\circ} \mathrm{C}, 20^{\circ} \mathrm{C}$ and $40^{\circ} \mathrm{C}$ are respectively $5.18 \mathrm{~mm}, 3.481 \mathrm{~mm}, 4.173 \mathrm{~mm}$. Error is respectively $10.5 \%$, $8.5 \%, 8.1 \%$. Stress peak values are respectively $460 \mathrm{MPa}, 452.1 \mathrm{MPa}, 431.7 \mathrm{MPa}$. Error is respectively $11.8 \%, 9.8 \%, 6.9 \%$. Welding stress and deformation results meet the requirement of engineering application. It proves accuracy of simulation results. When environment temperature is $0^{\circ} \mathrm{C}$ or $40^{\circ} \mathrm{C}$, deformation is more than that of $20^{\circ} \mathrm{C}$. Welding deformation and residual stress are larger at $0^{\circ} \mathrm{C}$, so welding operation should be avoided in the low temperature environment.

\section{Introduction}

In engineering machinery, box structure is stability. It determines welding deformation is relatively small [1]. As the core part of screed, ironing plate is required to be flat, so it is designed typical box structure. Deformation caused by welding has a direct influence on the flatness of bottom surface. By comparison of products deformation after one year, it is found that deformation occurs a certain deviation. Even if the deviation is only $1 \mathrm{~mm}$, but it will affect the thickness of cutting stock, machining allowance, and even repairing welding. It has been mature for research mechanism of joint welding [2-4]. However, research on environmental temperature in engineering application is very few, and production application is less.

In this research, box structure ironing plate is as the research object. Using thermal elastic plastic method of finite element analysis, it obtains ironing plate deformation and residual stress distribution of three environmental temperature at $0^{\circ} \mathrm{C}, 20^{\circ} \mathrm{C}$ or $40^{\circ} \mathrm{C}$ by comparative analysis. It verifies deformation and residual stress by feeler gauge and $\mathrm{X}$ ray diffraction method.

\section{Test preparation and test methods}

Test preparation. Material of Ironing plate is Q345B. The length of ironing plate is $1500 \mathrm{~mm}$. The width is $350 \mathrm{~mm}$. The height is $250 \mathrm{~mm}$. The height of connection plate is $410 \mathrm{~mm}$. The ironing plate is shown in Fig. 1. It is welded by Matsushita YD-350KR2 welding machine, and welding wire is ER50-6. The diameter of welding wire is $1.2 \mathrm{~mm}$. Welding parameters are shown in table 1.

Test methods. Test uses the same batch of plate and the same manufacturers to reduce differences. In order to better characterize the factors of environmental temperature, test samples selected meet the following two conditions. First condition is test sample in different seasons of one year. Second condition is welding temperature close to test requirment temperature of the season. Environmental 


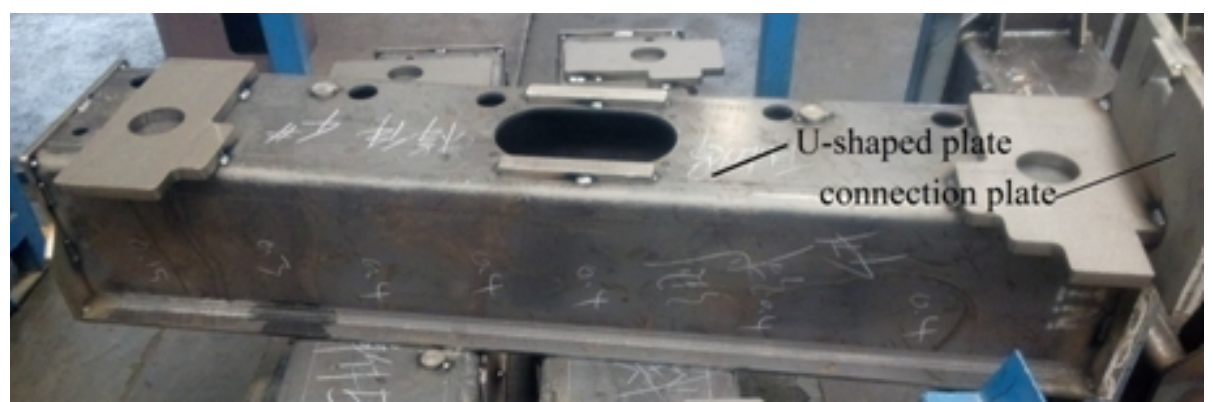

Fig. 1 The solid model of ironing plate

Table 1 Welding parameters

\begin{tabular}{c|c|c|c}
\hline Arc voltage [V] & Arc current $[\mathrm{A}]$ & Welding speed $[\mathrm{mm} / \mathrm{s}]$ & gas flow rate[L/min] \\
\hline $280-300$ & $26-28$ & $32-34$ & 20 \\
\hline
\end{tabular}

temperature of ironing plate manufacture is measured using high temperature infrared thermometer HT-6888. It tests residual stress near the position of weld seams by iXRD named portable X ray analyzer.

In order to ensure accuracy of residual stress test results, it needs to clean rust, oil and oxide layer of ironing plate surface. Then polish on the surface, and makes the surface expose metallic luster, and roughness is less than $20 \mu \mathrm{m}$. Residual stress is tested with the choice of chromium target.Start the equipment. Voltage is $25 \mathrm{kV}$, and current is $5 \mathrm{~mA}$. It verifies by the virtual of zero stress calibration, and absolute error should be kept within 14Mpa. If error is big, it should modify parameters. The calibration error must be in the allowed range, then it works.

\section{Establish the finite element model}

Ignoring the flow of welding molten pool, it is defined as quasi steady state. Elements based on life-death technique are used to activate. Weld prefabricated grids are filled. In order to ensure accuracy of residual stress, double ellipsoid heat source fully considers the characteristic of heat source [5]. According to design requirements of welding process, with weld bead height of $6 \mathrm{~mm}$, $7 \mathrm{~mm}, 10 \mathrm{~mm}$ and different height, T-joint of heat source macro morphology is respectively tested as shown in figure 2. It measures welding high, bead width, penetration depth and heat affected zone, and grids of weld seams are filled.
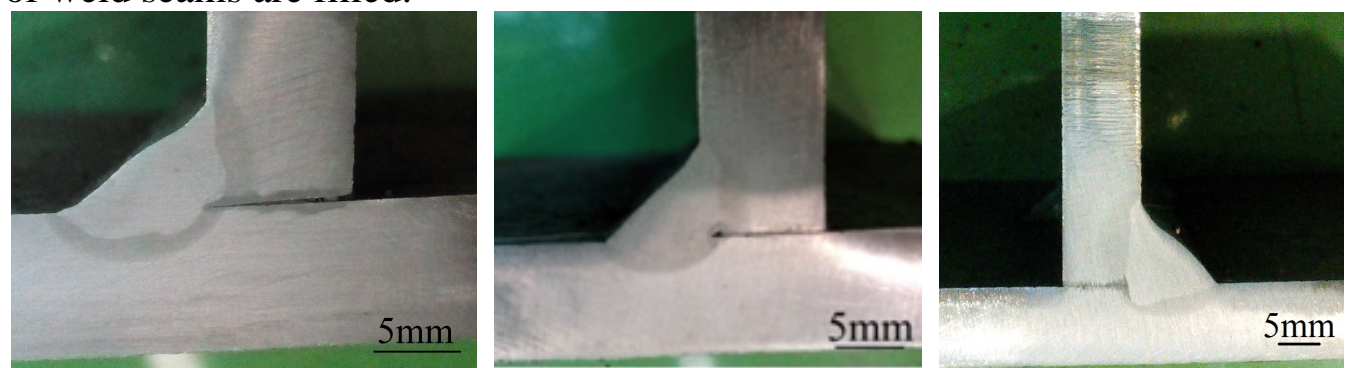

(a) Weld bead height is $6 \mathrm{~mm}$ (b) Weld bead height is $7 \mathrm{~mm}$ (c) Weld bead height is $10 \mathrm{~mm}$

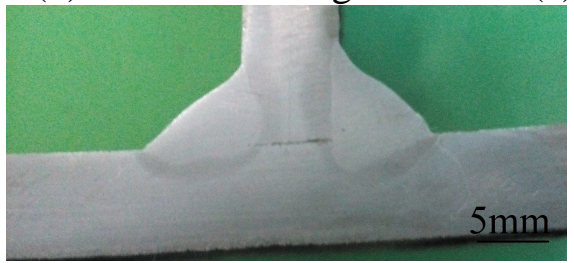

(d) Different weld bead height

Fig. 2 Heat resource

In order to reduce the number of grids, it deals with dense grid in weld seams and heat-affected zone. It adopts sparse grid away from weld seams. Mesh model of ironing plate is shown in Figure 3. Grid size of weld seam is $2 \mathrm{~mm}$. The number of grid unit is 106631 . The number of node is 152153 .

Simulation is used for materials of Q345B. Thermal physical and mechanics parameters of material change with temperature. It is shown in Figure 4. 


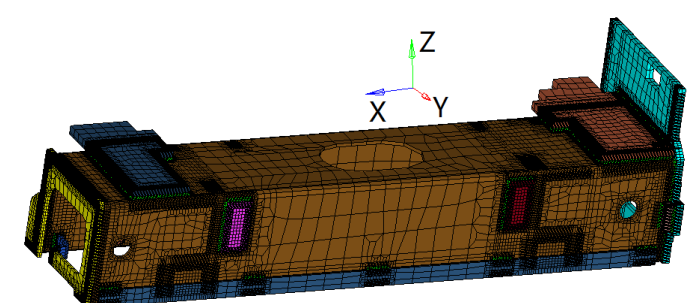

Fig. 3 Mesh model of ironing plate

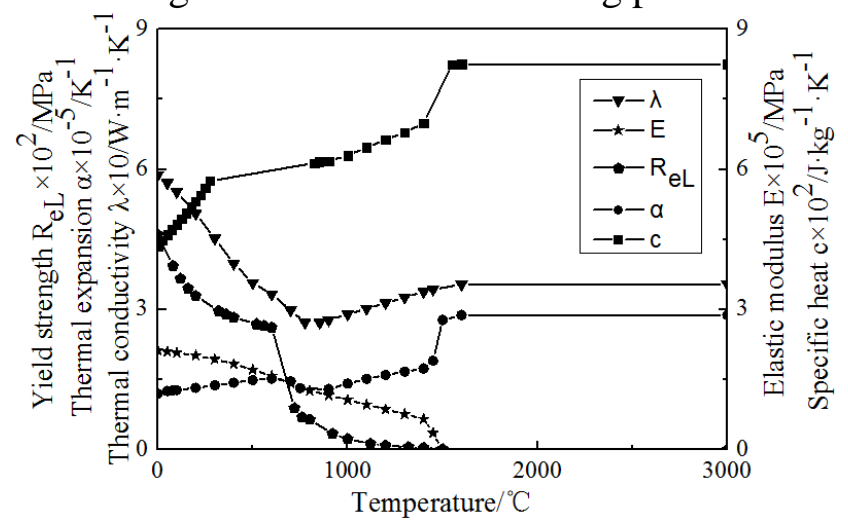

Fig. 4 Relationship between thermo-mechanical parameters and temperature of Q345B

Mechanical boundary conditions are set up by displacement constraint. It sets four groups of contact to definite the relation of welding platform and different surfaces of ironing plate. It is definition of constraints to restrict $\mathrm{X}$ direction in the middle section of $\mathrm{U}$-shaped plate to limit $\mathrm{X}$ direction contraction deformation. It is definition of constraints to restrict $\mathrm{XZ}$ displacement parallel with the middle free section of connection plate to limit $\mathrm{XZ}$ direction contraction deformation.

Using the Newton's law and Pohl Weitzman's law, it considers respectively of convection and radiation between the boom and external environment. The convection heat transfer coefficient is set to 0.02 . Considering local operating environment temperature, operation will be avoided at high and low environment temperature. It sets three kinds of environment temperature of $0^{\circ} \mathrm{C}, 20^{\circ} \mathrm{C}$ and $40^{\circ} \mathrm{C}$.

\section{Simulation results analysis and experimental verification}

The influence of environment temperature on welding deformation. It obtains welding deformation at environment temperature of $0^{\circ} \mathrm{C}, 20^{\circ} \mathrm{C}$ and $40^{\circ} \mathrm{C}$ as shown in figure 5 .

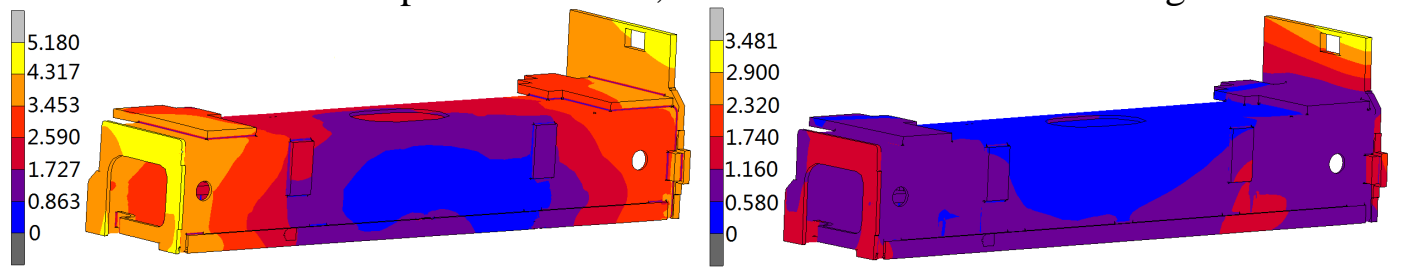

(a) Contour of environment temperature at $0^{\circ} \mathrm{C}$ (b)Contour of environment temperature at $20^{\circ} \mathrm{C}$

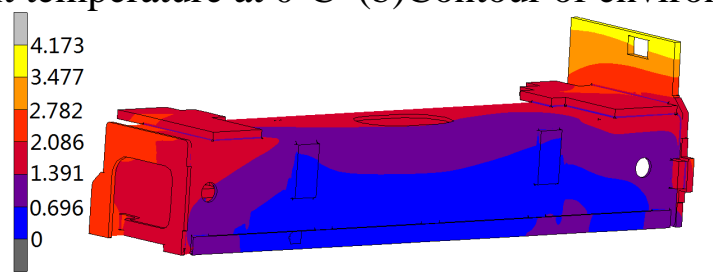

(c) Contour of environment temperature at $40^{\circ} \mathrm{C}$

Fig. 5 Contour of welding deformation

The result shows the maximum deformation appears in the upper side of connection plate as shown in figure 5. Deformation peak values at environmental temperature of $0^{\circ} \mathrm{C}, 20^{\circ} \mathrm{C}$ and $40^{\circ} \mathrm{C}$ are respectively $5.18 \mathrm{~mm}, 3.481 \mathrm{~mm}, 4.173 \mathrm{~mm}$. It is mainly due to weld contraction, and makes deformation to the side of weld seam. Deformation trend is convex on the bottom of U-shaped plate. It causes weld seam shrinkage on both sides of connection plate effect, and releases deformation on 
the bottom of U-shaped plate. Deformation occurs to center concave on the two sides of connection plate. It is coincides with T-joint typical deformation trend. Free end is warping. The maximum deformation of bottom plate appears near the ends of connection plate. Deformation peak values at environmental temperature of $0^{\circ} \mathrm{C}, 20^{\circ} \mathrm{C}$ and $40^{\circ} \mathrm{C}$ are respectively $4.396 \mathrm{~mm}, 2.459 \mathrm{~mm}, 2.831 \mathrm{~mm}$.

Through comparison of welding results at different environmental temperature, it can be seen that welding deformation at environment temperature of $0^{\circ} \mathrm{C}$ and $40^{\circ} \mathrm{C}$ is higher than that of $20^{\circ} \mathrm{C}$. Thus considering of machining and assembly process, it avoids manufacturing in high and low environment temperature. It contributes to reduce rework and machining difficulty, even direct assembly processing without machining.

The influence of environment temperature on residual stress. It obtains residual stress at environment temperature of $0^{\circ} \mathrm{C}, 20^{\circ} \mathrm{C}$ and $40^{\circ} \mathrm{C}$ as shown in figure 6.
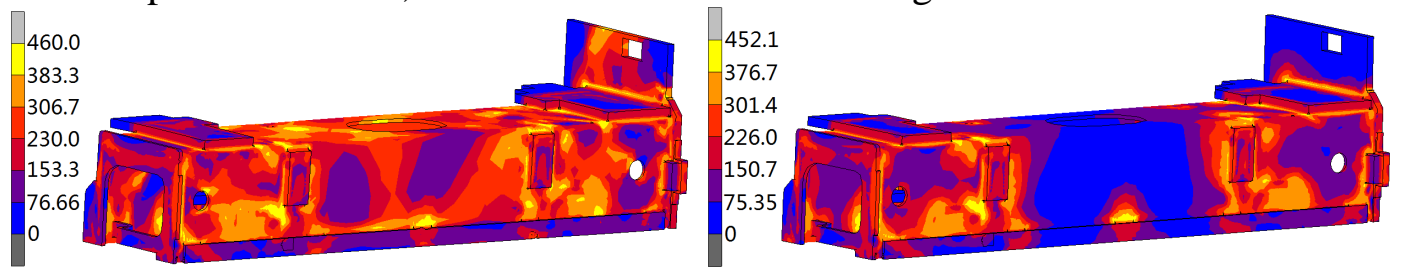

(a) Contour of environment temperature at $0^{\circ} \mathrm{C}$ (b)Contour of environment temperature at $20^{\circ} \mathrm{C}$

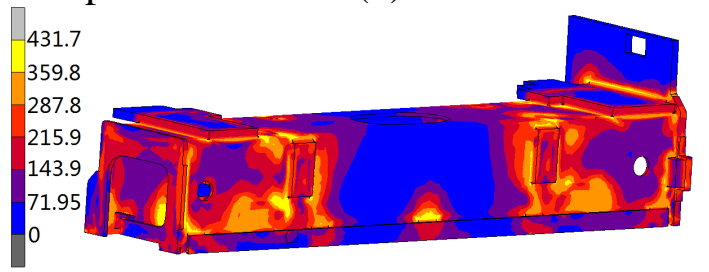

(c) Contour of environment temperature at $40^{\circ} \mathrm{C}$

Fig. 6 Contour of residual stress

Figure 6 shows that stress distribution trend is the same at different environment temperature. Stress near weld seams is larger, and stress peak value is similar. Stress peak values at environmental temperature of $0^{\circ} \mathrm{C}, 20^{\circ} \mathrm{C}$ and $40^{\circ} \mathrm{C}$ are respectively $460 \mathrm{MPa}, 452.1 \mathrm{MPa}, 431.7 \mathrm{MPa}$. It is obvious that the influence of residual stress distribution is very small when environment temperature is $20^{\circ} \mathrm{C}$ and $40^{\circ} \mathrm{C}$. However, when environment temperature is $0^{\circ} \mathrm{C}$, residual stress distribution is larger, which is directly related to heat dissipation by low temperature difference. The internal of U-shaped plate is heated in the work. It will further promote the release of stress, which will cause second deformation. It directly affects ironing pavement quality. It makes great harm, and should avoid working under low temperature environment in winter.

Simulation results analysis and verification. By the virtue of feeler, it measures deformation in the bottom of U-shaped plate. Results show maximum deformation appears near the ends of connection plate. It is consistent with simulation trend. The average value of maximum deformation is calculated in three groups of different environmental temperature. The resluts are as shown in table 2.

Table 2 Measurements of deformation

\begin{tabular}{c|c|c|c|c|c|c|c|c|c}
\hline Environmental temperature & \multicolumn{3}{|c|}{$0^{\circ} \mathrm{C}$} & \multicolumn{3}{c|}{$20^{\circ} \mathrm{C}$} & \multicolumn{3}{c}{$40^{\circ} \mathrm{C}$} \\
\hline Before welding [mm] & 0.56 & 0.22 & 0.44 & 0.36 & 0.63 & 0.31 & 0.42 & 0.45 & 0.52 \\
\hline After welding [mm] & 4.45 & 4.35 & 4.35 & 2.7 & 2.8 & 2.6 & 2.95 & 3.15 & 3.25 \\
\hline difference value[mm] & 3.89 & 4.13 & 3.91 & 2.34 & 2.17 & 2.29 & 2.53 & 2.6 & 2.73 \\
\hline
\end{tabular}

Table 2 shows that the average value of welding deformation at environmental temperature of $0^{\circ} \mathrm{C}$, $20^{\circ} \mathrm{C}$ and $40^{\circ} \mathrm{C}$ is respectively $3.88 \mathrm{~mm} 、 2.20 \mathrm{~mm} 、 2.62 \mathrm{~mm}$. Error is respectively $10.5 \%, 8.5 \%, 8.1 \%$. It proves accuracy of simulation results. At the same time, it can be found that simulation results are in good agreement with experimental results with environmental temperature rising.

Test chooses one of structure at different environment temperatures. The distance from point $\mathrm{A}$ is $62 \mathrm{~mm}, 94 \mathrm{~mm}, 156 \mathrm{~mm}, 1877.5 \mathrm{~mm}$ as shown in Figure 7 (a). Residual stress distribution is shown in Figure 7 (b). Figure 7 (b) shows that stress distribution trend is consistent, and stress value decreases with the increase of environment temperature. Error at environmental temperature of $0^{\circ} \mathrm{C}, 20^{\circ} \mathrm{C}$ and 
$40^{\circ} \mathrm{C}$ is respectively $11.8 \%, 9.8 \%, 6.9 \%$, and meets the requirement of engineering application. The fluctuation of stress at environment temperature of $20^{\circ} \mathrm{C}$ and $40^{\circ} \mathrm{C}$ is relatively smaller than that of $0^{\circ} \mathrm{C}$, so welding is avoided to work under low temperature environment.

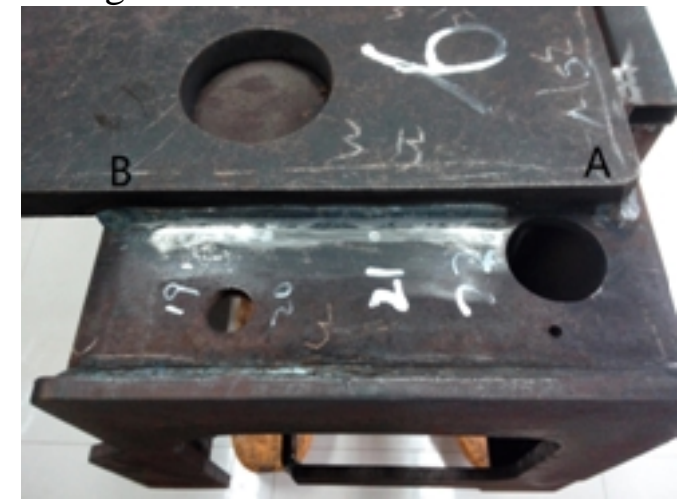

(a)Experimental measurement

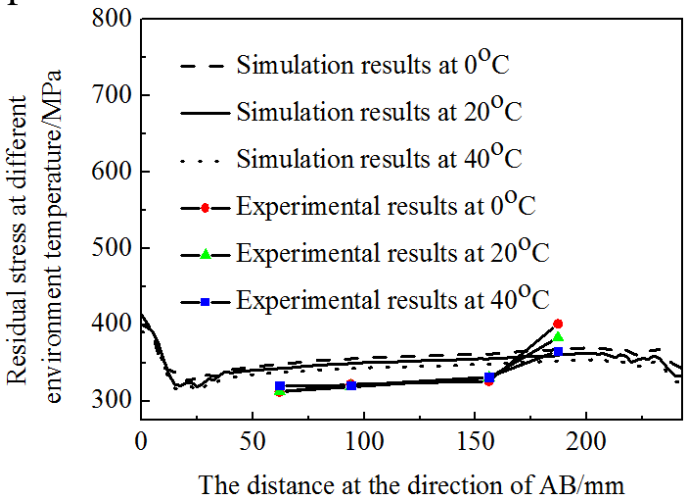

(b)Residual stress distribution

Fig. 7 Experimental measurement and residual stress distribution

\section{Conclusions}

Resaerch shows that it simulates welding process of box structure ironing plate at different environment temperature of $0^{\circ} \mathrm{C}, 20^{\circ} \mathrm{C}$ and $40^{\circ} \mathrm{C}$. It predicts deformation and stress distribution. It measures deformation before and after welding in aid of feeler. It measures residual stress with $\mathrm{X}$ ray diffraction stress measurement. It verifies simulation results by experiments. The following conclusions are drawn in the resarch.

(1) The maximum deformation appears in the upper side of connection plate. Welding deformation at environment temperature of $0^{\circ} \mathrm{C}$ and $40^{\circ} \mathrm{C}$ is higher than that of $20^{\circ} \mathrm{C}$.

(2) Deformation trend is convex on the bottom of U-shaped plate. Deformation occurs to center concave on the two sides of connection plate.

(3) Stress distribution trend is the same at different environment temperature. Stress near weld seams is larger, and stress peak value is similar.

(4) The fluctuation of deformation and stress at environment temperature of $0^{\circ} \mathrm{C}$ is relatively large, so welding is avoided to work under low temperature environment.

In this study, deformation of ironing plate in the work cannot be close to actual situation. Residual stress distribution changes more complex. On the basis of finite element model, it studies heated asphalt in inner U-shaped plate to simulate actual situation, and further studies the process.

\section{Acknowledgements}

This work was financially supported by the Jiangsu Natural Science Foundation (BK20140229), and National Science and Technology Support Program (2015BAF07B02).

\section{References}

[1] X. T. Tian: Welding Structure (China Machine Press Publications, China 1982).

[2] C. S. Wu, H. LU, and Y. H. Wei: Welding \& Joining Vol. 1 (2012), p. 10-22.

[3] D.Deng: Materials and Design Vol. 49 (2013), p. 1022-1033.

[4] Y. Ueda, H. Murakawa, N. Ma: Welding deformation and residual stress prevention. (Elsevier, New York 2012).

[5] Y. B. FANG, Y. WANG, L. P. ZHANG, C. WANG and X.H. ZHAN: Electric Welding Machine Vol. 46, No. 9 (2016), p. 92-96. 